\title{
Utilization of Industrial Waste Heat in Cooling and Air/Conditioning Applications
}

\author{
Saeed M. Al-Noman, Ahmed Abdullah Al-Balawi \\ Saudi Electricity Company, Saudi Arabia
}

\begin{abstract}
Cooling and air/conditioning are considered critical necessities in residential, commercial and industrial utilities particularly in Saudi Arabia due to extremely hot weather. Current conventional cooling technologies especially in industrial applications require high power consumption to run electrical compressors and chillers. Also, the environment has been negatively affected by the pollution of fossil-fuel power plants in addition to the impact of harmful refrigerants which are used in cooling systems. Therefore, future trends should be focused on innovative solutions to overcome these challenges. One significant solution is to utilize the industrial waste heat by implementing sorption cooling technologies. However, deployment of sorption cooling technologies in power sector requires huge efforts due to various challenges such as system complexity and the probable intervention with existing systems in the plants. The objective of the current study is to discuss these challenges and present possible opportunities of industrial waste heat utilization for cooling applications.
\end{abstract}

Keywords: district; cooling; sorption; industrial; applications 